\title{
DESAIN DAPUR UMUM PORTABLE UNTUK PENANGGULANGAN BENCANA ALAM
}

\author{
Andi Farid Hidayanto \\ Staf Pengajar Jurusan Desain, Politeknik Negeri Samarinda \\ E-mail: gandhyie@yahoo.com \\ Anna Rulia \\ Staf Pengajar Program Studi Arsitektur, Jurusan Desain, \\ Politeknik Negeri Samarinda \\ E-mail: anna.rulia@yahoo.co.id
}

\begin{abstract}
Indonesia is prone to disaster. In dealing with disasters, especially in meeting the needs of the logistics required for the victims eating soup kitchen. Common kitchen that exist today are generally in the form of tents, houses are used as shelters, or modified cars. Common kitchen there was an emergency, sober, and its location can not approach the scene.

Of this problem is in the design of a common kitchen for natural disaster relief, which can meet the needs of officers, as well as victims. The resulting soup kitchen design can accommodate logistics taste, giving space for officers, protected from external environmental conditions, and can be placed in a location close to the scene. In general kitchen design is done by Pahl and Beitz method in the design of products with the steps that Planning and explanation task, the concept of product design, product design shape, and design details. For data collection using the Individual Questionnaire and Focus Group Discussion This result will be obtained attributes required in the design.

The results of the research is a common kitchen design for a portable natural disaster easily assembled and disassembled, can be established at the site of diverse, easy to operate, and is able to accommodate facilities and needs. Common kitchen designs produced in the form of large-scale three-dimensional model, a blueprint for technical specifications, which can proceed to the production phase.

Keywords: natural disasters, design, soup kitchen, portable.
\end{abstract}


Andi Farid Hidayanto, Anna Rulia, Desain Dapur Umum Portable Untuk Penanggulangan Bencana Alam

\section{Abstrak}

Indonesia merupakan daerah rawan bencana. Dalam menangani bencana, utamanya dalam pemenuhan kebutuhan logistik makan untuk para korban diperlukan dapur umum. Dapur umum yang ada saat ini umumnya berupa tenda peleton, rumah (bangunan) yang dijadikan posko, atau mobil yang dimodifikasi. Dapur umum yang ada sifatnya darurat, seadanya dan lokasinya tidak bisa mendekati tempat kejadian.

Dari masalah tersebut perlu didesain dapur umum untuk penanggulangan bencana alam, yang bisa memenuhi kebutuhan, petugas maupun korban. Desain dapur umum yang dihasilkan mampu menampung logistik secukupnya, memberi ruang untuk petugas, terlindungi dari kondisi lingkungan luar, dan bisa ditempatkan di lokasi dekat kejadian.

Dalam mendesain dapur umum ini dilakukan dengan metode Pahl dan Beitz dalam perancangan produk dengan langkah-langkah yaitu Perencanaan dan penjelasan tugas, Perancangan konsep produk, Perancangan bentuk produk, dan Perancangan detail. Untuk pengumpulan data menggunakan metode Individual Questionnaire dan Focus Group Discussion yang hasilnya ini akan didapatkan atribut yang diperlukan dalam desain.

Hasil dari penelitian berupa desain dapur umum untuk penanggulangan bencana alam yang portable mudah dirakit dan dibongkar, bisa didirikan di lokasi yang beraneka ragam, mudah dioperasikan, serta mampu menampung fasilitas dan kebutuhan. Desain dapur umum yang dihasilkan dalam bentuk model tiga dimensi berskala, blue print spesifikasi teknis, yang bisa dilanjutkan ke tahap produksi.

Kata Kunci: bencana alam, desain, dapur umum, portable.

\section{PENDAHULUAN}

Indonesia merupakan daerah rawan bencana. Akhir-akhir ini sering terdengar berita bencana yang melanda di wilayah Indonesia. Antara lain banjir, kebakaran, gempa, gunung meletus, longsor, kecelakaan di sungai, daerah terisolir, kerusakan akibat tambang. Dalam menangani penanggulangan bencana, seperti dalam pemenuhan kebutuhan logistik, utamanya makan untuk para korban dan petugas, diperlukan dapur umum.

Dapur umum untuk penanggulangan bencana alam yang ada saat ini biasanya dari tenda peleton, rumah/posko yang dijadikan dapur atau mobil lapangan. Pendirian dapur umum saat ini masih dianggap seadanya, seperti tenda yang diikat ke pohon, rumah penduduk yang dijadikan posko, atau mobil terbuka. Dapur umum yang ada juga belum bisa menampung fasilitas pendukung, misalnya ruang istirahat, peralatan, tempat logistik, dan ruang beraktifitas. Dimensi dan ruang dapur umum juga terbatas sehingga gerak aktiftas tidak leluasa (Arie Sulistyanto, 2009).

Lantai dapur umum yang ada sekarang umumnya kontak langsung dengan tanah dan tidak terlindungi dari efek hujan, becek, tanah gembur dan tanah tidak rata. Akibatnya lantai mudah kotor dan tidak higienis. Posisi petugas beraktifitas di dalamnya tidak ergonomis, sehingga jika dilakukan dalam jangka waktu lama tidak nyaman dan menimbulkan kelelahan (Terbit Setya). Karena bersifat darurat, pendirian dapur umum mengutamakan kecepatan yang sering tanpa diimbangi persiapan matang. Tidak jarang fasilitas yang ada tidak memadai dan ribet dalam penataan peralatan (Dyat Agung). Pendirian dapur umum juga jauh dari lokasi bencana, karena tidak bisa dirakit di tempat kejadian bencana.

Dari kondisi tersebut diperlukan dapur umum untuk bencana, dimana dapur umum tersebut bersifat kompak, mudah dalam pengoperasian, dapat dipindah- 
Vol. 2, No. 1, Oktober 2014

pindah, mampu menampung peralatan yang diperlukan, dan fasilitas yang dibutuhkan petugas. Dapur umum bisa dikomposisikan dengan tenda -tenda lainnya, secara modular. Dapur umum hasil desain bisa diaplikasikan untuk beberapa pengguna, antara lain pemerintah daerah, PMI, Dinas Sosial, dan lembaga yang berkepentingan dengan dapur umum. Dapur umum yang didesain bersifat portable, sehingga bisa dikirim ke tempat yang memerlukan. Proses pembuatannya bisa di industri manufaktur sederhana, sehingga bisa diproduksi massal untuk menekan biaya produksi.

\section{II.BAHAN DAN METODE PENELITIAN}

Perancangan merupakan kegiatan awal dari usaha merealisasikan suatu produk yang kebutuhannya sangat dibutuhkan oleh masyarakat. Setelah perancangan selesai maka kegiatan yang menyusul adalah pembuatan produk. Kedua kegiatan tersebut dilakukan dua orang atau dua kelompok orang dengan keahlian masing-masing, yaitu perancangan dilakukan oleh tim perancang dan pembuatan produk oleh tim kelompok pembuat produk. Dalam merancang dapur umum untuk bencana alam ini penulis menggunakan metode dan langkah-langkah desain dari Pahl dan Beitz.

Pahl dan Beitz mengusulkan cara merancang produk sebagaimana yang dijelaskan dalam bukunya; Engineering Design: A Systematic Approach. Cara merancang Pahl dan Beitz tersebut terdiri dari 4 kegiatan atau fase, yang masingmasing terdiri dari beberapa langkah. Keempat fase tersebut adalah:

1. Perencanaan dan penjelasan tugas

2. Perancangan konsep produk

3. Perancangan bentuk produk (embodiment design)

4. Perancangan detail

Setiap fase proses perancangan berakhir pada hasil fase, seperti fase pertama menghasilkan daftar persyaratan dan spesifikasi perancangan. Hasil setiap fase tersebut kemudian menjadi masukan untuk fase berikutnya dan menjadi umpan balik untuk fase yang mendahului. Perlu dicatat pula bahwa hasil fase itu sendiri setiap saat dapat berubah oleh umpan balik yang diterima dari hasil fase-fase berikutnya.

\section{HASIL DAN PEMBAHASAN}

Dalam mendesain tenda dapur umum ini ditentukan dulu kriteria-kriteria desainnya. Hal ini digunakan sebagai acuan desain yang akan dihasilkan. Adapun kriteria tersebut yaitu:

1. Material. Dapur dari metarial yang aman. Tidak mudah terbakar, tidak mudah sobek. Mudah didapatkan di pasaran.

2. Ruang. Dimensi cukup memenuhi untuk beraktifitas petugas di dalamnya. Mampu menampung logistik dan peralatan memasak. Tersedia ruang terbuka dan ruang tertutup untuk hal-hal yang tidak diakses oleh umum.

3. Proses produksi. Dapur bisa diproduksi di industri manufaktur sederhana

4. Alur sirkulasi. Dapur mempertimbangan faktor ergonomi, serta ruang sirkulasi keluar masuk, alur beraktifitas di dalamnya. Memiliki area pandang yang bebas, serta memberikan kenyamanan. Tersedia sirkulasi udara, sehingga suhu di dalamnya nyaman untuk aktifitas.

5. Tanda/sign. Dapur memiliki tandatanda yang menunjukkan dapur, area, serta papan penunjuk yang diperlukan

6. Pemasangan. Tenda didesain mudah untuk dibongkar/pasang. Tenda terdiri dari beberapa komponen, 
Andi Farid Hidayanto, Anna Rulia, Desain Dapur Umum Portable Untuk Penanggulangan Bencana Alam

yaitu alas, kerangka, badan tenda. Tenda juga bisa dirangkai dengan tenda sejenis di sebelahnya, bila komposisi terdiri dari beberapa tenda. Dapur bersifat mobile dan portable, agar bisa dikirim ke lokasi dengan medan berbagai kondisi.

7. Desain. Dapur umum memiliki unsur estetika (desain) yang indah sesuai kaidah desain yang baku.

Dalam desain dapur umum perlu didata aktiftas yang terjadi di dalamnya. Dari aktifitas-aktifitas tersebut akan diperoleh kebutuhan yang diperlukan. Beberapa aktifitas tersebut antara lain ditunjukkan dalam tabel 1 di bawah ini:

Dari aktifitas tersebut akan didapat data kebutuhan dalam dapur yang memerlukan fasilitas. Kebutuhan tersebut bisa merupakan bagian dari desain dapur, namun bisa juga bukan dari desain dapur. Tentunya dengan menempatkan fasilitas dalam dapur, dan fasilitas tersebut diperoleh dari luar. Sehingga fasilitas tersebut bukan merupakan bagian dari desain dapur umum. Fasilitas tersebut antara lain: meja, kursi, tempat sampah, perkakas memasak.

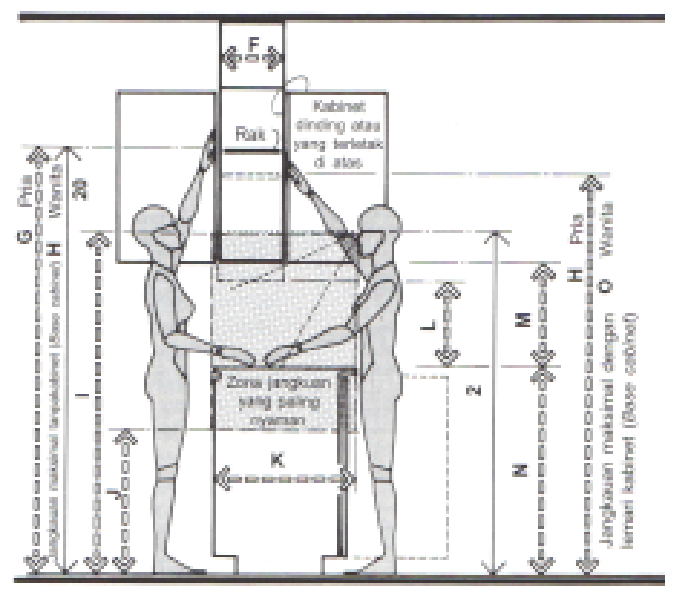

Gambar 1. Acuan dimensi ruang

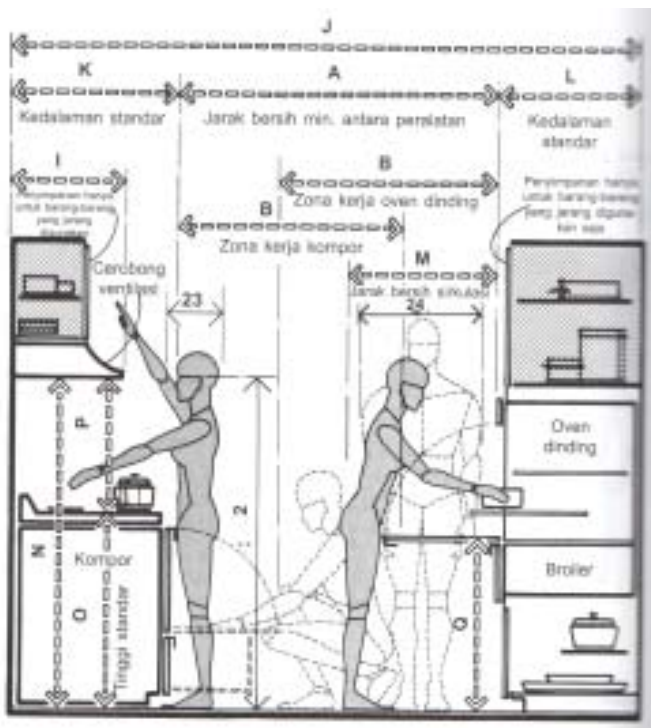

Gambar 2. Acuan dimensi ruang

Tabel 1. Aktiftas di dapur

\begin{tabular}{|c|l|l|}
\hline No & \multicolumn{1}{|c|}{ Aktifitas } & \multicolumn{1}{c|}{ Kebutuhan } \\
\hline 1 & Keluar/masuk tenda & Pintu \\
\hline 2 & Jalan, jongkok & Area sirkulasi \\
\hline 3 & Duduk, berdiri & Kursi, area sirkulasi \\
\hline 4 & Mengambil, menaruh barang & Lemari, rak, meja \\
\hline 5 & Mengambil, membuang sampah & Tempat sampah \\
\hline 6 & Melihat tanda & Tanda petunjuk \\
\hline 7 & Proteksi dari tanah & Alas, lantai \\
\hline 8 & Memasak & Perkakas dapur \\
\hline 9 & Meracik & Perkakas dapur \\
\hline 10 & Mendirikan/membongkar dapur & System \\
\hline 11 & Menyimpan dapur & System \\
\hline
\end{tabular}


Tabel 2. Acuan dimensi ruang

\begin{tabular}{|c|c|l|c|}
\hline No & Kode & \multicolumn{1}{|c|}{ Keterangan } & Dimensi (cm) \\
\hline 1 & A & Jarak antar peralatan & 121,9 min \\
\hline 2 & G & Jangkauan tangan & 200 \\
\hline 3 & K & Lebar meja kerja/jarak perkakas ke dinding & $61-66$ \\
\hline 4 & M & Jarak sirkulasi & 76,2 \\
\hline 5 & N & Tinggi meja kerja & $88,9-91,4$ \\
\hline
\end{tabular}

Dalam mendesain produk, pertama yang ditekankan adalah penentuan konsepnya. Karena dari konsep ini, semua unsur desain akan mengancu pada konsep tersebut. Selanjutnya dilakukan desain awal, yang terdiri dari beberapa alternatif desain. Dari beberapa alternatif desain, dipilih satu desain terpilih. Selanjutnya desain terpilih tersebut dikembangkan sehingga menjadi desain final. Desain final tersebut dilengkapi spesifikasi teknis baku agar bisa diproduksi. Dari beberapa alternatif desain, terpilih desain final seperti gambar 3-4 di bawah ini.

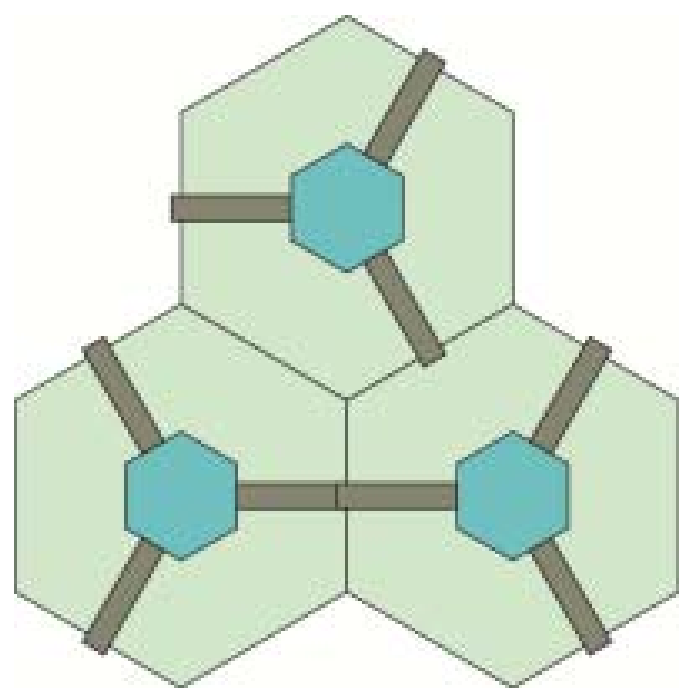

Gambar 3. Beberapa Kombinasi desain

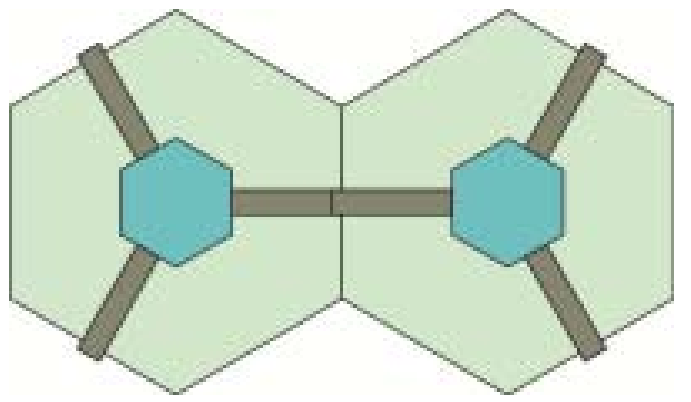

Gambar 4. Beberapa Kombinasi desain
Dari desain terpilih, disusun beberapa alternatif konfigurasi ruang dalam dapur umum (lay-out) atau blocking area yang menunjukkan penempatan/akomodasi aktifitas dan fasilitas di dalamnya. Alokasi blocking area mengacu pada data ergonomi untuk menentukan dimensi-dimensinya. Konfigurasi ruang tersebut seperti ditunjukkan dalam gambar 5 - 6 di bawah ini:

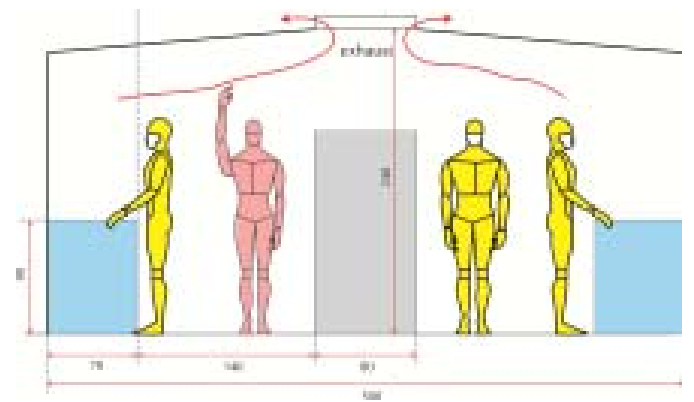

Gambar 5. Lay-out ruang

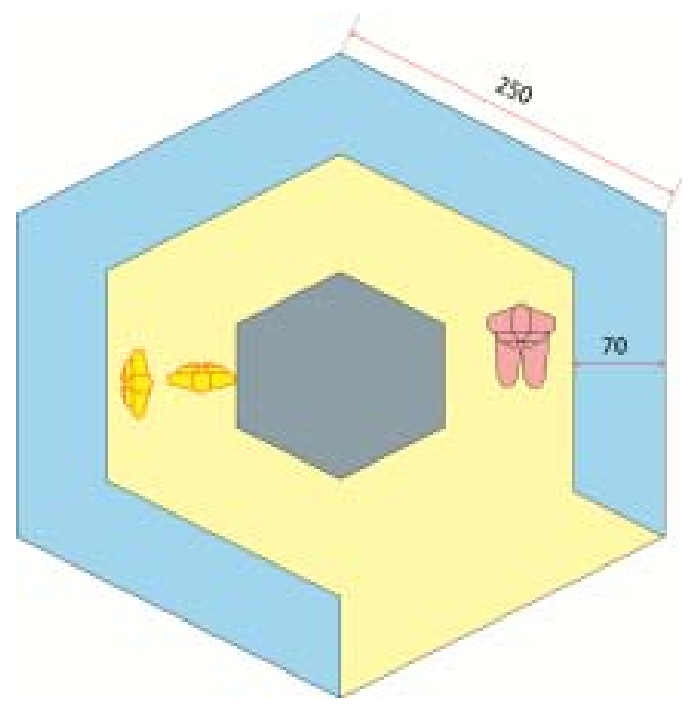

Gambar 6. Lay-out ruang 
Andi Farid Hidayanto, Anna Rulia, Desain Dapur Umum Portable Untuk Penanggulangan Bencana Alam

Dari blocking area, dikembangkan area sirkulasi aktifitas di dalamnya. Dilanjutnya dengan penentuan ukuran dimensi baku sesuai acuan data anthropometri serta toleransinya. Maka didapatkan ukuran teknis produk hasil desain. Hasil desain produk tersebut bisa dilihat pada gambar 7 - 11 di bawah ini:

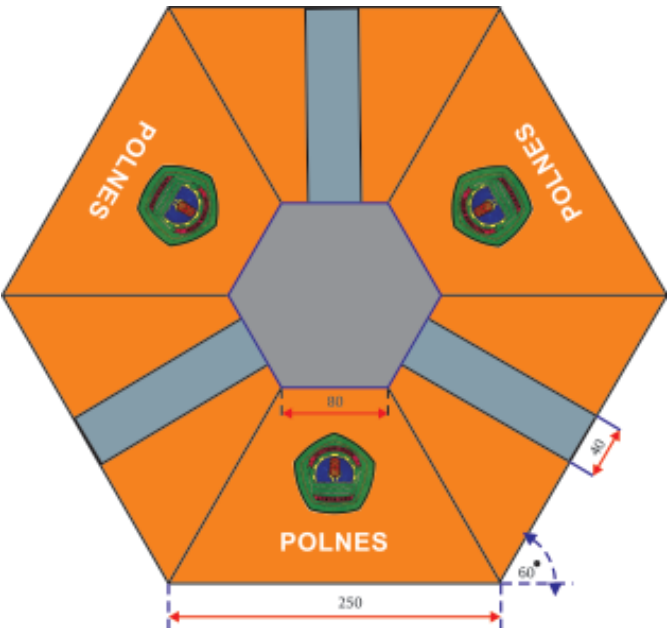

Gambar 7. Tampak Atas

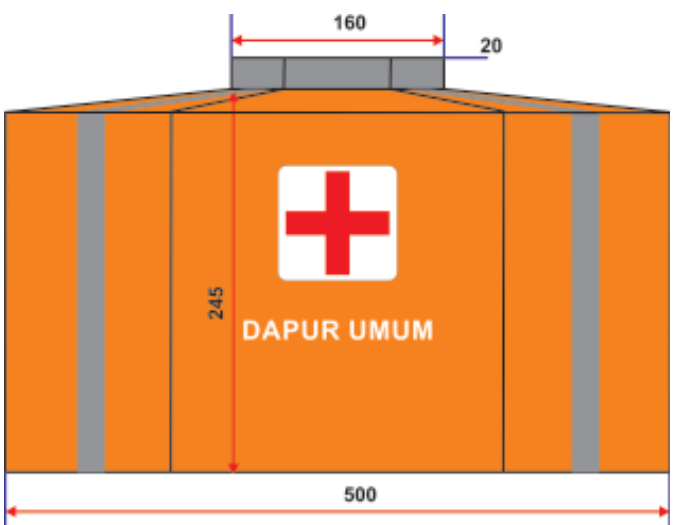

Gambar 8. Tampak samping

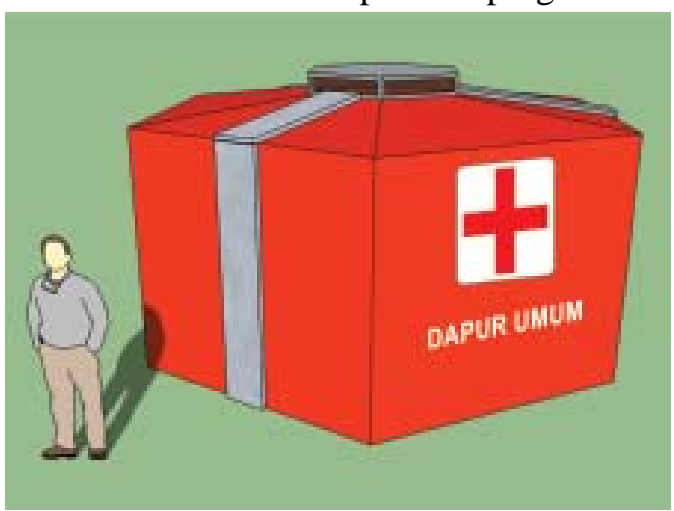

Gambar 9. Isometri produk

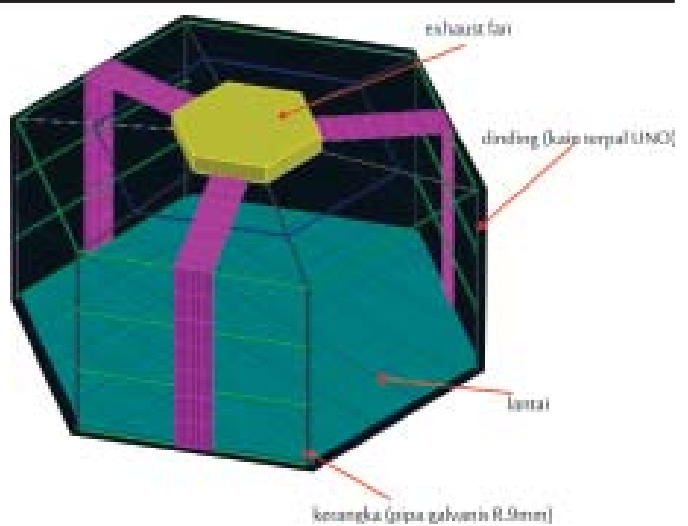

Gambar 10. Konstruksi tenda

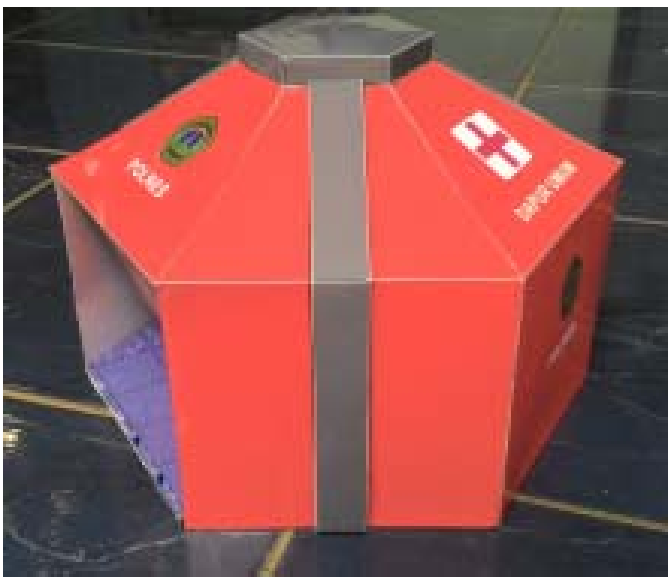

Gambar 11. Model skala produk

Pemberian warna pada produk merupakan hal mutlak sebagai bagian dari desin. Dengan penggunaan warna maka produk akan dikenali oleh konsumen. Baik bentuk, kegunaan, fungsi, kepemilikan. Pemberian warna meliputi warna produk, asesoris (grafis), tanda-tanda (sign) petunjuk, keterangan, label.

Pemberian warna tersebut yaitu:

1. Bodi. Menggunakan warna yang cerah, mudah dilihat. Bodi meliputi dinding, atap. Warna yang cerah antara lain putih, oranye, hijau toska. Dalam hal ini digunakan warna oranye, sebagai pertimbangan warna ini lazim dipakai oleh badan penangggulangan bencana. Warna oranye mudah dilihat, tidak menyilaukan mata, memancarkan 
Vol. 2, No. 1, Oktober 2014

cahaya, sehingga cepat menarik perhatian. Bersifat hangat.

2. Kerangka menggunakan warna Material sendiri yang diekspos, yaitu warna galvanis. Untuk penguat dinding menggunakan warna mirip kerangka.

3. Ilustrasi dan tanda. Dalam tenda diberi ilustrasi dan tanda-tanda sebagai petunjuk. Tanda-tanda tersebut bisa menjadi bagian dari tenda, atau bisa berdiri sendiri yang diletakkan di dalam tenda. Tanda petunjuk tersebut umumnya adalah: masuk, keluar, tempat sampah, tempat cuci, awas bahaya api, dan lain-lain. Diberi Lambang institusi sebagai identitas bahwa produk ini didesain oleh institusi yang bersangkutan. Lambang PMI dan tulisan “Dapur Umum” sebagai identitas fungsi produk tersebut.

Dalam produk dapur umum ini material penyusunnya, yaitu:

1. Lantai, menggunakan flooring sebagai alas dengan system puzzle knockdown, sehingga mudah dibawa dan dibersihkan. Dimensi flooring adalah panjang $60 \mathrm{~cm}$, lebar $60 \mathrm{~cm}$, dan tebal $5 \mathrm{~cm}$. lebar dan panjang lantai ini disesuaikan dengan dimensi keramik yang ada, sehingga bila kondisi tertentu bisa diganti dengan keramik yang ukurannya umum di pasaran.

2. Dinding, kain. Material untuk dinding dari kain. Kain yang tersedia antara lain terpal jenis Uno, nylon, Terpal Plastik /Tarpauline Plastic. Bahan yang dipakai adalah terpal jenis Uno. Bahan jenis ini memiliki jaringan serat kuat, dan tahan terhadap jamur.
3. Atap. Bahan untuk atap sam dengan bahan untuk dinding, karena dapurnya jenis tenda.

4. Kerangka atap. Kerangka atap menggunakan pipa galvanis.

5. Kerangka dinding. Untuk kerangka dinding sama dengan atap yaitu pipa galvanis.

Hasil desain dapur umum berupa produk yang ini mudah untuk dirangkai, mudah dirakit, bisa didirikan di lokasi dekat bencana, mampu mengakomodasi kebutuhan dan aktifitas petugas. Dengan bentuk yang modular sehingga portable, mudah dibawa untuk didistribusikan. Diharapkan dengan konstruksi ini mudah untuk perawatan sehingga menekan biaya perawatan.

\section{KESIMPULAN}

Salah satu unsur dalam manajemen penanggulangan bencana alam adalah dapur umum. Dapur umum digunakan untuk mobilisai bantuan berupa penyaluran kebutuhan makanan dan logistik. Ada bermacam-macam jenis dapur umum, dengan segala kelebihan dan kekurangan masing-masing. Dari penelitian ini dihasilkan desain dapur umum untuk bencana alam. Dapur umum yang dihasilkan dalam bentuk tenda, karena bentuk tenda memiliki beberapa kelebihan. Antara lain, mudah dipasang, mudah dibongkar, portable, modular, bisa didistrubusikan ke lokasi bencana. Dapur umum ini bisa dikombinasikan beberapa dapur sejenis membentuk formasi bangunan sesuai kondisi dan kebutuhan di lapangan.

Tentunya bentuk dengan sifat dan konsep ini masih memerlukan beberapa pembenahan agar lebih sempurna. Dapur umum perlu penyempurnaan dengan bahannya yang lebih kuat, susunan kerangkanya, sistem perakitannya, serta strukturnya, sehingga mudah diterjemahkan oleh industri manufaktur untuk diproduksi massal. 
Andi Farid Hidayanto, Anna Rulia, Desain Dapur Umum Portable Untuk Penanggulangan Bencana Alam

\section{Daftar Pustaka}

Nurmianto, Eko, Ergonomic Design for Mobile and Portable Emergency Disaster Kitchen, $3^{\text {rd }}$ International Conference on Operations and Supply Chain Management, Malaysia

Saginatari, Diandra Pandu (2011), Dapur Bersih dan Dapur Kotor, Skripsi Fakultas Teknik, Departemen Arsitektur, Universitas Indonesia, Jakarta

Sulistiyanto, Arie, 2009. Desain Dapur Umum Dengan Konsep Kompaktor, Jurnal Desain Idea, Vol 7. No. 2, 2009

www.digilib.its.ac.id/Terbit Setya/Desain dapur Umum Untuk Penanganan Bencana Alam Dengan Konsep Modul.htm, 17 April 2013

www.digilib.its.ac.id/Dyat Agung Syahputra/Desain dapur Umum Untuk Pasca Bencana Dengan Konsep Karavan.htm, 17 April 2013

www.its.ac.id/Rancang Dapur Umum Portable untuk Korban Bencana.htm, 29 April 2013 www.dinassosialpropinsikaltim.go.id/kaltim resmi punya perda penanggulangan bencana daerah.htm, 29 April 2013

www.RescueForHumanity/Pengantar Dapur Umum.htm, 22 Juni 2013 